\title{
Pendekatan Malcolm Baldrige Criteria For Performance Excellent (Education Criteria) dalam Perancangan Sistem Pengukuran Kinerja Fakultas Teknik Univeritas Udayana menuju Sertifikasi AUN-QA
}

\author{
I Made Dwi Budiana P1)*, I Made Gatot Karohika1) \\ 1)Program Studi Teknik Mesin Univ. Udayana, Jimbaran, Bali, Indonesia \\ Naskah diterima 28/09/2020; direvisi 08/11/2020; disetujui 14/11/2020 \\ doi: https://doi.org/10.24843/JEM.2020.v13.i02.p06
}

\begin{abstract}
Abstrak
Fakultas Teknik Unud merupakan salah satu Fakultas yang berada di lingkungan Universitas Udayana. Fakultas Teknik memiliki 5 jurusan yang memiliki peminat banyak. Saat ini Fakultas Teknik sedang mempersiapkan diri untuk mendukung Universitas Udayana memperoleh sertifikasi Asean University Network - Quality Assurance (AUN-QA) yang ditargetkan di visitasi tahun 2021. Salah satu pendukung dalam perolehan sertifikasi tersebut adalah Fakultas Teknik harus memiliki sistem pengukuran kinerja. Penelitian ini merancang sistem pengukuran kinerja yang terintregasi melalui pendekatan Malcolm Baldrige Criteria For Performance Excellent (Education Criteria) yang diintregasikan dengan beberapa metode lainnya yaitu IPMS yang digunakan untuk menentukan Indikator Penentu Kinerja atau sering dikenal dengan Key Performande Indicator (KPI). Setelah itu KPI dibobotkan menggunakan metode Analytical Hierarcy Process (AHP). Setelah KPI memiliki bobot kemudian dilakukan scoring secara menyeluruh dengan Metode Objectives Matrix (OMAX) sehingga dihasilkan angka indeks per periode yang menjadi acuan tingkat kinerja jurusan, serta Traffic Light System (TLS) untuk mengetahui KPI mana yang memerlukan perbaikan berdasarkan warna. Dengan terciptanya sistem pengukuran kinerja yang terintegrasi diharapkan Fakultas Teknik dapat melakukan perbaikan secara terus menerus. Dari Hasil penelitian didapat Performance Indicator dari Fakultas Teknik pada periode ini adalah 427,19 dengan $24 \mathrm{KPI}$ yang diukur. Performance Indicator tersebut menunjukkan bahwa secara keseluruhan Kinerja Fakultas Teknik berada diatas rata-rata (300). Hanya 2 kategori yang berada pada zona merah sebesar $21 \%$ yaitu Kriteria Mahasiswa (KPI 1 dan KPI 4) dan Kriteria Manajemen (KPI 18, KPI 19, dan KPI 20). Pada tahun berikutnya Fakultas Teknik harus berfokus terhadap kelima KPI terebut agar nantinya dapat meningkatkan kinerja.
\end{abstract}

Kata kunci: Malcolm Baldrige Criteria For Performance Excellent (Education Criteria), metode IPMS, Key Performance Indicator (KPI), metode Analytical Hierarcy Process (AHP)

\begin{abstract}
The Faculty of Engineering, Udayana University is one of the faculties in Udayana University. The Faculty of Engineering has 5 departments that have a lot of interest. Currently, the Faculty of Engineering is preparing to support Udayana University in obtaining the Asean University Network - Quality Assurance (AUN-QA) certification which is targeted for a visitation in 2021. One of the supporters in obtaining this certification is that the Faculty of Engineering must have a performance measurement system. In this research using an integrated performance measurement system that designed through the Malcolm Baldrige Criteria For Performance Excellent (Education Criteria) approach which is integrated with several methods, namely IPMS in determining the Key Performance Indicator (KPI) which becomes a determining indicator of later performance. assisted by using the Analytical Hierarchy Process (AHP) method in giving the weight of each KPI. After the KPI has a weight, then a comprehensive scoring is carried out using the Objectives Matrix (OMAX) method so that an index number per period is generated which is the reference for the level of performance of the department, as well as a Traffic Light System (TLS) to find out which KPIs require improvement based on color. With the creation of an integrated performance measurement system, it is hoped that the Faculty of Engineering can make continuous improvements. The results showed that the Performance Indicator from the Faculty of Engineering in this period was 427.19 with $24 \mathrm{KPIs}$ being measured. The Performance Indicator shows that the overall performance of the Faculty of Engineering is above average (300). Only 2 categories are in the red zone of $21 \%$, namely Student Criteria (KPI 1 and KPI 4 ) and Management Criteria (KPI 18, KPI 19, and KPI 20). In the following year, the Faculty of Engineering must focus on the five $\mathrm{KPIs}$ so that later they can improve performance.
\end{abstract}

Keywords: Malcolm Baldrige Criteria For Performance Excellent (Education Criteria), IPMS method, Key Performance Indicator (KPI), Analytical Hierarchy Process (AHP) method

\section{Pendahuluan}

Asean University Network - Quality Assurance (AUN-QA) dibentuk sebagai jaringan penjamin mutu pendidikan tinggi di lingkungan negara-negara Asean, dengan mendukung dan mengembangkan penjaminan mutu di institusi tinggi, meningkatkan kualitas pendidikan tinggi, serta membangun kolaborasi dengan organisasi penjaminan mutu baik regional maupun internasional untuk kemajuan pendidikan di negaranegara Asean. Sertifikasi AUN - QA ini merupakan salah satu langkah didalam Universitas Udayana didalam meraih status World Class University di tahun 2024'

Untuk mendukung sertifikasi AUN - QA tersebut, pada Fakultas Teknik perlu memiliki suatu sistem pengukuran yang terintegrasi. Dimana sistem tersebut bertujuan untuk mengontrol produktivitas yang telah dicapai dari periode ke periode berikutnya, apakah mengalami kenaikan atau penurunan sehingga pimpinan dapat segera mengambil target kebijakan 
terhadap KPI yang mengalami penurunan kinerja [1]. Hasil monitoring tersebut dapat juga sebagai masukan untuk tim penjaminan mutu internal baik di tingkat Fakultas UP3M maupun TPPM di tingkat Program Studi. Pemantauan terhadap seluruh proses tersebut maka diharapkan Fakultas Teknik bisa menghasilkan lulusan yang berkualitas dan terstandarisasi. Untuk dapat menerapkan perbaikan secara terus menerus (continous improvement), maka dalam penelitian kali ini dilakukan Analisis, perancangan dan implementasi sistem pengukuran kinerja. Banyak metode yang dapat digunakan dalam pembuatan system ini. Dalam penelitian ini pendekatan yang digunakan adalah metode Malcolm Baldrige Criteria for Performance Excellent (Education Criteria) dimana tujuan dari metode ini salah satunya adalah sebagai alat manajemen untuk memahami dan mengelola kinerja serta pedoman perencanaan dan kesempatan untuk pembelajaran [2] yang digabungkan dengan beberapa metode yaitu Metode OMAX, metode Integrated IPMS, AHP dan TLS. Analytical Hierarcy Process (AHP) serta Traffic Light System (TLS).

\section{Metode Penelitian}

Tahapan pelaksanaan penelitan dijelaskan di bawah ini.

\subsection{Lokasi Penelitian}

Lokasi Penelitian adalah di Fak Teknik Univ Udayana Kampus Bukit Jimbaran dan Kampus Unud Jalan PB Sudirman Denpasar Bali.

2.2. Pemilihan Metode Pengukuran Produktivitas

Terdapat banyak metode yang dapat digunakan dalam merancang sistem pengukuran kinerja dimana masing masing metode memiliki kelebihan dan kekurangan. Dalam penelitian ini digunakan beberapa metode yang diintregasikan menjadi satu. Adapaun metode tersebut adalah Metode Malcolm Baldrige Criteria for Performance Excellent Education Criteria (MBCfPE), Metode Objectives Matrix (OMAX), Integrated Performance Measurement Systems (IPMS), Analytical Hierarcy Process (AHP) serta Traffic Light System.

\subsection{Jenis dan Metode Pengumpulan Data}

Sebelum dilakukan pengolahan data, dilakukan terlebih dahulu pengumpulan data. Jenis data yang dikumpulkan adalah data primer dan data sekunder.

\subsection{Identifikasi Indikator-Indikator atau Kriteria} Produktivitas yang Akan Diukur.

Langkah awal yang harus dilakukan adalah penentuan $\mathrm{KPI}$ dengan kombinasi metode MBCfPE dan metode IPMS. Adapaun langkah-langkah sebagai berikut:

1. Stakeholder requirement.

KPI merupakan kumpulan dari sejumlah kebutuhan pada pemangku kepentingan yang berhubungan langsung dengan Fakultas Teknik Unud seperti mahasiswa, orang tua mahasiswa, pimpinan fakultas dan program studi, instansi pengguna lulusan baik negeri maupun swasta, masyarakat, serta lingkungan lainnya.

\section{External Monitorin}

Pengukuran kinerja perusahaan profit maupun non profit memerlukan Benchmarking [3]. Untuk mengetahui kinerja Fakultas Teknik, perlu dilakukan pembandingan terhadap Fakultas - fakultas Teknik dari Universitas lain yang dianggap sebagai pesaing.

3. Menentukan ukuran-ukuran kinerja (measures) yang biasa disebut KPI.

2.5. Pemberian Bobot Dari Masing-Masing KPI Yang Diukur

Untuk dapat mencapai indeks akhir dalam sitem pengukuran kinerja, maka perlu dilakukan pembobotan pada masing - masing KPI yang telah di rumuskan pada Langkah sebelumnya. Pemberian bobot dari masingmasing KPI dimulai dari pembuatan Hierarki KPI, penyusunan, penyebaran, pengisian kuisioner. Setelah isian dinyatakan konsisten $(C R<0,1)[4]$ maka langkah selanjutnya pemberian bobot pada maisng-masing KPI 2.6. Pengolahan Data Atau Pengukuran Kriteria Produktivitas

Setelah data-data terkumpul dari hasil penelitian yang dilakukan maka langkah selanjutnya adalah melakukan pengukuran, pengolahan, dan analisa pada tiap-tiap periode tahun yang ditetapkan masing-masing $\mathrm{KPI}$ dengan menggunakan metode yang telah ditetapkan sehingga tingkat produktivitas setiap tahunnya dapat ditentukan.

2.7. Evaluasi Produktivitas

Setelah pengukuran produktivitas dilakukan maka selanjutnya adalah evaluasi berdasarkan data pengukuran terhadap masing-masing KPI yang telah dianalisis dan disajikan melalui suatu laporan produktivitas. Selanjutnya hasil evaluasi ini akan dapat ditentukan KPI-KPI yang mengalami kenaikan ataupaun penurunan tiap tahunnya untuk dilakukan langkah perbaikan pada periode berikutnya terhadap $\mathrm{KPI}$ yang mengalami penurunan

\section{Hasil dan Pembahasan}

Pendekatan yang dilakukan untuk menentukan kriteria produktivitas adalah melalui pendekatan dengan Metode MBCfPE dan IMPS. Adapun hasil rekapitulasi dari kuisioner yang di sebarkan disajikan pada Tabel 1. Dari Tabel 1 terlihat KPI yang akan diukur melalui formula KPI yang tertera dalam tabel.

\subsection{Perancangan Pengukuran Kinerja dengan Metode Objectives Matrix (Omax)}

Langkah selanjutnya adalah pembuatan sistem pengukuran kinerja berbasis OMAX. Dari tabel diatas ditentukan $24 \mathrm{KPI}$ yang akan diukur. Pada tabel OMAX terdapat skor dari 0 sampai 10 yang dibuat berdasarkan perhitungan rata - rata, BKA, BKB dari data-data historis beberapa periode sebelumnya. Berikut perhitungan skor utnuk KPI 1 dengan mengambil data diambil dari 47 program studi yang tersebar di seluruh Univeritas Udayana. Dari 47 data tersebut, dicari rata-rata dan standar deviasi. Rata-rata digunakan sebagai skor 3. Skor 0 ditentukan dari Batas Kontrol Bawah (BKB) dan skor 10 ditentukan dari Batas Kontrol Atas (BKA). Hasil pengoperasioan Model Omax ditunjukkan dalam Tabel 2 dan 3. 
Tabel 1. Formula KPI

\begin{tabular}{|c|c|c|}
\hline MBCfPE & OBJECTIVES & $\begin{array}{l}\text { Key Performance } \\
\text { Indicators (KPI) }\end{array}$ \\
\hline \multirow{10}{*}{$\begin{array}{l}\text { - Perencana } \\
\text { an } \\
\text { Strategis } \\
\text { - Fokus } \\
\text { pasar dan } \\
\text { pelanggan } \\
\text { - Fokus } \\
\text { sumber } \\
\text { daya } \\
\text { manusia }\end{array}$} & \multirow{5}{*}{$\begin{array}{l}\text { Peningkatan } \\
\text { Kualitas } \\
\text { Mahasiswa }\end{array}$} & - $\quad$ Rasio IPK mahasiswa \\
\hline & & $\begin{array}{ll} & \text { Rasio lulus tepat } \\
\text { waktu }\end{array}$ \\
\hline & & - $\quad$ Rasio lulusan aktif \\
\hline & & $\begin{array}{ll}\text { - } & \text { Rasio PKM didanai } \\
& \text { Dikti }\end{array}$ \\
\hline & & $\begin{array}{l}\text { Rasio penerima } \\
\text { beasiswa }\end{array}$ \\
\hline & \multirow{5}{*}{$\begin{array}{l}\text { Peningkatan } \\
\text { Kualitas } \\
\text { Dosen }\end{array}$} & $\begin{array}{l}\text { Rasio Guru besar per } \\
\text { dosen tetap }\end{array}$ \\
\hline & & $\begin{array}{ll}\text { - } & \text { Rasio S3 per dosen } \\
\text { tetap }\end{array}$ \\
\hline & & $\begin{array}{ll} & \text { Rasio dosen } \\
\text { mahasiswa }\end{array}$ \\
\hline & & $\begin{array}{ll} & \text { Rasio Serdos per } \\
\text { dosen tetap }\end{array}$ \\
\hline & & $\begin{array}{l}\text { Rasio penelitian \& } \\
\text { pengabdian per } \\
\text { dosen tetap }\end{array}$ \\
\hline \multirow{7}{*}{$\begin{array}{l}\text { - Pengukura } \\
\text { n, Analisis, } \\
\text { dan } \\
\text { Manajemen } \\
\text { Pengetahu } \\
\text { an } \\
\text { - Hasil - } \\
\text { hasil }\end{array}$} & \multirow{7}{*}{$\begin{array}{l}\text { Peningkatan } \\
\text { jumlah } \\
\text { Publikasi } \\
\text { Karya Ilmiah }\end{array}$} & $\begin{array}{ll} & \text { Rasio scopus per } \\
& \text { jumlah dosen tetap }\end{array}$ \\
\hline & & $\begin{array}{l}\text { Rasio Jurnal } \\
\text { Internasional per } \\
\text { dosen tetap } \\
\end{array}$ \\
\hline & & $\begin{array}{ll}- & \text { Rasio jurnal } \\
\text { terakreditasi per } \\
\text { dosen }\end{array}$ \\
\hline & & $\begin{array}{l}\text { - } \quad \text { Rasio buku referensi } \\
\text { per dosen tetap }\end{array}$ \\
\hline & & $\begin{array}{l}\text { Rasio paten per } \\
\text { dosen tetap }\end{array}$ \\
\hline & & $\begin{array}{l}\text { Rasio hak cipta per } \\
\text { dosen tetap }\end{array}$ \\
\hline & & $\begin{array}{l}\text { Rasio proseding } \\
\text { internasional per } \\
\text { dosen tetap }\end{array}$ \\
\hline \multirow{7}{*}{$\begin{array}{l}\text { - } \text { Kepemimpi } \\
\text { nan } \\
\text { - } \text { Manajemen } \\
\text { proses }\end{array}$} & \multirow{7}{*}{ Manajemen } & $\begin{array}{ll}\text { - } & \text { Koefisien Kehadiran } \\
& \text { Pegawai }\end{array}$ \\
\hline & & $\begin{array}{l}\text { - Koefisien Kehadiran } \\
\text { Dosen }\end{array}$ \\
\hline & & - $\quad$ Kuisioner Online PBM \\
\hline & & $\begin{array}{l}\text { - } \quad \text { Rasio mahasiswa } \\
\text { lolos per peminat }\end{array}$ \\
\hline & & $\begin{array}{ll}\text { - } & \text { Rasio mahasiswa } \\
& \text { regristasi per peminat }\end{array}$ \\
\hline & & $\begin{array}{l}\text { Rasio MOU dengan } \\
\text { instansi lain. }\end{array}$ \\
\hline & & $\begin{array}{l}\text { - } \quad \text { Nilai kepuasan } \\
\text { pengguna terhadap } \\
\text { mutu alumni. }\end{array}$ \\
\hline
\end{tabular}

Tabel 2. Penentuan Rasio, Skor 0, Skor 3, skor 10 Pada KPI 1

\begin{tabular}{|l|c|c|}
\hline Standar Deviasi & & 0,0477 \\
\hline D.A & & $5 \%$ \\
\hline C.L & & $95 \%$ \\
\hline K & Skor 3 & 0,7843 \\
\hline Rata-rata Atas & Skor 10 & 0,8796 \\
\hline $\begin{array}{l}\text { Batas Kontrol } \\
\text { (BKA) }\end{array}$ & 0,6889 \\
\hline $\begin{array}{l}\text { Batas Kontrol Bawah } \\
\text { (BKB) }\end{array}$ & Skor 0 \\
\hline
\end{tabular}

Tabel 3. Penentuan Nilai OMAX Pada KPI 1

\begin{tabular}{|c|c|}
\hline SKOR & NILAI \\
\hline 10 & 0,8796 \\
\hline 9 & 0,8660 \\
\hline 8 & 0,8524 \\
\hline 7 & 0,8387 \\
\hline 6 & 0,8251 \\
\hline 5 & 0,8115 \\
\hline 4 & 0,7979 \\
\hline 3 & 0,7843 \\
\hline 2 & 0,7525 \\
\hline 1 & 0,7207 \\
\hline 0 & 0,6889 \\
\hline
\end{tabular}

\subsection{Hasil Implementasi Pengukuran Kinerja}

Dari contoh perhitungan di atas, kemudian dilakukan langkah yang sama terhadap $24 \mathrm{KPI}$. Range skor 0-10 menunjukkan kinerja masing - masing KPI. Skor 0 merupakan kondisi kinerja terburuk dan ini merupakan kondisi yang benar - benar harus menjadi perhatian pempinan. Skor 10 merupakan pencapain kinerja terbaik. Jika nantinya Fakultas telah mencapai score 10 berarti Tabel Omax harus diperbaharui dengan target yang lebih tinggi. Demikian seterusnya sehingga perbaikan kinerja secara terus menerus (continous improvement) dapat dilakukan.

Tabel 4 merupakan tabel Pengukuran Kinerja Model OMAX. Berikut penjelasan dari masing - masing komponen yang terdapat dalam tabel tersebut yaitu :

- KPI yang didapat dari stakeholder requirements (kebutuhan pemangku kepentingan) yaitu $24 \mathrm{KPI}$.

- Performace adalah pencapain masing - masing $\mathrm{KPI}$ pada periode pengukuran.

- Score merupakan posisi KPI saat pengukuran dala minterval kelas 0 sampai 10.

- Weight adalah bobot masing - masing KPI yang diperoleh dari pembobotan dengan metode AHP.

- Value adalah hasil kali score dan weight terlihat bahwa pencapaian kinerja s

- Performance Indicator merupakan penjumlahan semua value dari KPI pada saat periode pengukuran.

KPI 1 pada saat pengukuran memiliki nilai 0,730 sehingga berada pada score 2. Dari pembobotan AHP, $\mathrm{KPI} 1$ memiliki weight 3,25\% sehingga value dari KPI 1 adalah $0,730 \times 3,2543=6,509$. Demikian seterusnya dengan perhitungan yang sama sampai dengan KPI 24. Setelah didapat value dari seluruh KPI, maka dijumlahkan menghasilkan Performance Indicator saat pengukuran yaitu sebesar 427,19. 
Jika dianalisa dengan menggunakan Traffic Light System dimana sistem tersebut mengelompokkan KPI berdasarkan warna sebagai berikut:

- Merah yang berarti dibawah rata-rata dan perlu perhatian khusus untuk diperbaiki kinerjanya. Adapun KPI yang dikelompokkan dalam kategori lampu merah adalah $\mathrm{KPI}$ yang memiliki skor 0,1, dan 2. Jumlah KPI yang berada pada kategori merah adalah sebesar $21 \%$ yaitu adalah KPI 1, KPI 4, KPI 18, KPI 19, dan KPI 20.

- Kuning merupakan KPI yang memiliki kinerja ratarata dengan rentangan skor 3 sampi 5. Jumlah KPI yang berada pada kategori kuning adalah sebesar $54 \%$ yaitu adalah KPI 2, KPI 5, KPI 6, KPI 7, KPI 8, KPI 9, KPI 10, KPI 12, KPI 13, KPI 14, KPI 15 dan $\mathrm{KPI} 17$
- Hijau merupakan KPI yang memiliki kinerja di atas rata-rata dengan rentangan skor 6 sampi 10. Jumlah $\mathrm{KPI}$ yang berada pada kategori hijau adalah sebesar $25 \%$ yaitu adalah KPI 3, KPI 11, KPI 16, KPI 21, KPI 22, dan KPI 23.

Performance Indicator tersebut menunjukkan bahwa secara keseluruhan Kinerja Fakultas Teknik berada diatas rata-rata (300). Hanya 2 kategori yang berada pada zona merah yaitu Kriteria Mahasiswa (KPI 1 dan KPI 4) dan Kriteria Manajemen (KPI 18, KPI 19, dan KPI 20). Pada tahun berikutnya Fakultas Teknik harus berfokus terhadap kelima KPI terebut agar nantinya dapat meningkatkan kinerja.

Tabel 4. Pengukuran Kinerja Model OMAX

\begin{tabular}{|c|c|c|c|c|c|c|c|c|c|c|c|c|c|c|c|c|c|c|c|c|c|c|c|c|}
\hline \multicolumn{25}{|c|}{ PENGUKURAN KINERJA MODEL OBJECTIVES MATRIX } \\
\hline \multicolumn{25}{|c|}{ FAKULTAS TEKNIK UNIVERSITAS UDAYANA } \\
\hline KP1 1 & $\mathrm{KPH} 2$ & $\mathrm{KOA3}$ & KO1 4 & KAS & K916 & k97 & Khs & kng & NA 10 & ตII & ตค1 12 & К11 & ติ14 & onis & (516 & ตบ & (518 18 & on 19 & $x=20$ & and & $\operatorname{lol} 2$ & Кด1 & KO 24 & KPI \\
\hline 0,700 & 0,400 & 0,974 & 0,12 & 0,224 & 0,068 & $0,3 n$ & 0,800 & 0,000 & 0,74 & 0,183 & 0,004 & 0,003 & 0,000 & 0.006 & 0,044 & 0.196 & 0,5004 & $0,1 \mathrm{~m}$ & 0,574 & $0,5 \% 6$ & 0,001 & 0.503 & 0,73 & PERFORMANCE \\
\hline 0,080 & 0,920 & 1,022 & 0,362 & 0.220 & 0,217 & 0,565 & 2,233 & \begin{tabular}{|l|l|}
1,124 \\
\end{tabular} & 1,048 & 0.265 & 0,32 & 0,239 & 0,45 & 0,000 & 0,035 & 0,756 & 1,210 & 0,660 & 0,920 & 0,653 & 0,724 & 0.53 & 1,340 & 10 \\
\hline 0,966 & 0,965 & 1,018 & 0,317 & 0,264 & 0,195 & 0,538 & 1,165 & 1,120 & 1,013 & 0.231 & 0,340 & 0,130 & $0,3 n$ & 0,013 & 0,031 & 0,60 & 1,168 & 0,623 & 0,910 & 0.624 & 0,650 & 0.539 & 1,269 & 9 \\
\hline 0,552 & 0,811 & 1,060 & 0,222 & 0,258 & 0,174 & 0,451 & 1,097 & 1,065 & $0,9 n$ & 0,200 & 0.006 & 0,17 & 0,330 & 0,015 & 0,000 & 0,617 & 1,12 & 0,506 & 0,500 & 0,55 & 0,607 & 0.505 & 1,157 & 8 \\
\hline 0,839 & 0,756 & 0,959 & 0,227 & 0,252 & 0,152 & 0,44 & 1,008 & 1,020 & 0,962 & 0.181 & 0.267 & 0,265 & 0.22 & 0,013 & 0,022 & 0,507 & 1,006 & 0,549 & 0,850 & 0,536 & 0.624 & 0,40 & 1,066 & 7 \\
\hline 0,825 & 0,02 & 0.900 & 0,181 & 0,245 & 0,110 & 0,397 & 0200 & \begin{tabular}{|l|l|}
0,955 \\
\end{tabular} & 0,966 & 0.153 & 0.29 & 0.12 & 0.234 & 0,010 & 0,018 & 0,48 & 1,04 & \begin{tabular}{|c|}
0.512 \\
\end{tabular} & 0,850 & 0,457 & 0,560 & 0,436 & 0,974 & 6 \\
\hline 0,811 & 0,647 & 0,980 & 0.136 & 0.239 & 0,100 & 0,200 & 0,832 & 0.91 & 0,871 & 0,125 & 0.180 & 0,058 & 0,10 & 0,000 & 0,033 & 0,208 & 1,003 & 0,474 & 0,80 & 0,458 & 0,57 & 0,402 & 0,883 & 5 \\
\hline 0,798 & 0,593 & 0,971 & 0,091 & 0.233 & 0,0 & 0,32 & 0,74 & 0.846 & 0,835 & 0,097 & 0,152 & 0,07 & 0,19 & 0,005 & 0,009 & 0,339 & \begin{tabular}{|l|l|}
0,561 \\
\end{tabular} & 0,437 & 0,850 & 0,419 & 0,513 & 0,368 & $a m$ & 4 \\
\hline 0,704 & 0,538 & 0,951 & 0,046 & $0,2 m$ & 0,066 & 0,255 & 0,656 & $0, m 1$ & 0.800 & 0,069 & 0.114 & 0,000 & 0,012 & 0,003 & 0,004 & $0 \times 2$ & 0,980 & 0,400 & 0,850 & 0,350 & 0,450 & 0,333 & $0, x 0$ & 3 \\
\hline 0,752 & 0,411 & 0,40 & $-0,059$ & 0,213 & 0,015 & 0,245 & 0,451 & \begin{tabular}{|l|}
0.663 \\
\end{tabular} & 0,727 & 0,000 & 0,024 & 0,008 & $-0,19$ & $-2,003$ & 0.066 & 0.106 & 0,83 & 0,313 & 0,827 & 0.259 & 0,452 & 0,233 & 0,457 & 2 \\
\hline 0,72 & 0,234 & 0,918 & 0,165 & 0,199 & 8,035 & 0,035 & 0,245 & \begin{tabular}{|l|l}
0,536 \\
\end{tabular} & 0,635 & 0,02 & 0,066 & 0,064 & 0,10 & $-0,08$ & 0,017 & 0,056 & $0, m$ & 0236 & 0,804 & 0,158 & 0,324 & 0,173 & 0,273 & 1 \\
\hline 0,609 & 0,157 & $0.8 \%$ & 0.270 & 0.185 & $-0,055$ & 0,05 & 0,040 & \begin{tabular}{|l|l|}
0,058 & \\
\end{tabular} & 0.552 & -0.127 & 0.153 & 0,121 & 0,241 & $-0,044$ & 0.027 & 0.218 & 0.600 & 0,240 & 0,300 & 0,107 & 0,246 & 0,053 & 0,060 & 0 \\
\hline 2 & 3 & 6 & 1 & 4 & 4 & 5 & 6 & 5 & 3 & 6 & \begin{tabular}{|l|}
3 \\
\end{tabular} & 3 & 3 & 5 & 6 & 3 & 0 & 1 & 0 & 9 & 7 & 10 & 4 & SCORE \\
\hline 1.25413 & 2.02670 & 215005 & 2.58 & 270060 & 2.4117: & 5,10060 & 6.51522 & 22540 & 6.0727 & $\cos 20$ & 200000 & $200 \mathrm{sec}$ & 20007 & $200 \mathrm{~m}$ & 2.600 & 220505 & 2.00506 & $5.12 \mathrm{me}$ & Анus & 4,23160 & 2049 & 4.2045s & 20670 & W0Gभ \\
\hline \multirow[t]{2}{*}{6.509} & 6,000 & 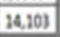 & 1.58 & $10 . \mathrm{m}$ & \begin{tabular}{|l|l|}
2,327 \\
\end{tabular} & $2, n$ & 39003 & $025 \times 1$ & 1423s & 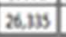 & $5, \mathrm{ses}$ & 7,050 & $\Delta x$ & $10.2 m$ & 20.65 & $\operatorname{sen} 1$ & 0.000 & \begin{tabular}{|l|l|l|} 
\\
\end{tabular} & 0,000 & ascoss & 32.32 & 41,45 & 12220 & value \\
\hline & & & & & & \multicolumn{6}{|c|}{427,19} & \multicolumn{6}{|c|}{300} & \multicolumn{6}{|c|}{$42,40 \%$} & $\begin{array}{l}\text { PERFORMANCE } \\
\text { INDICATOR }\end{array}$ \\
\hline
\end{tabular}

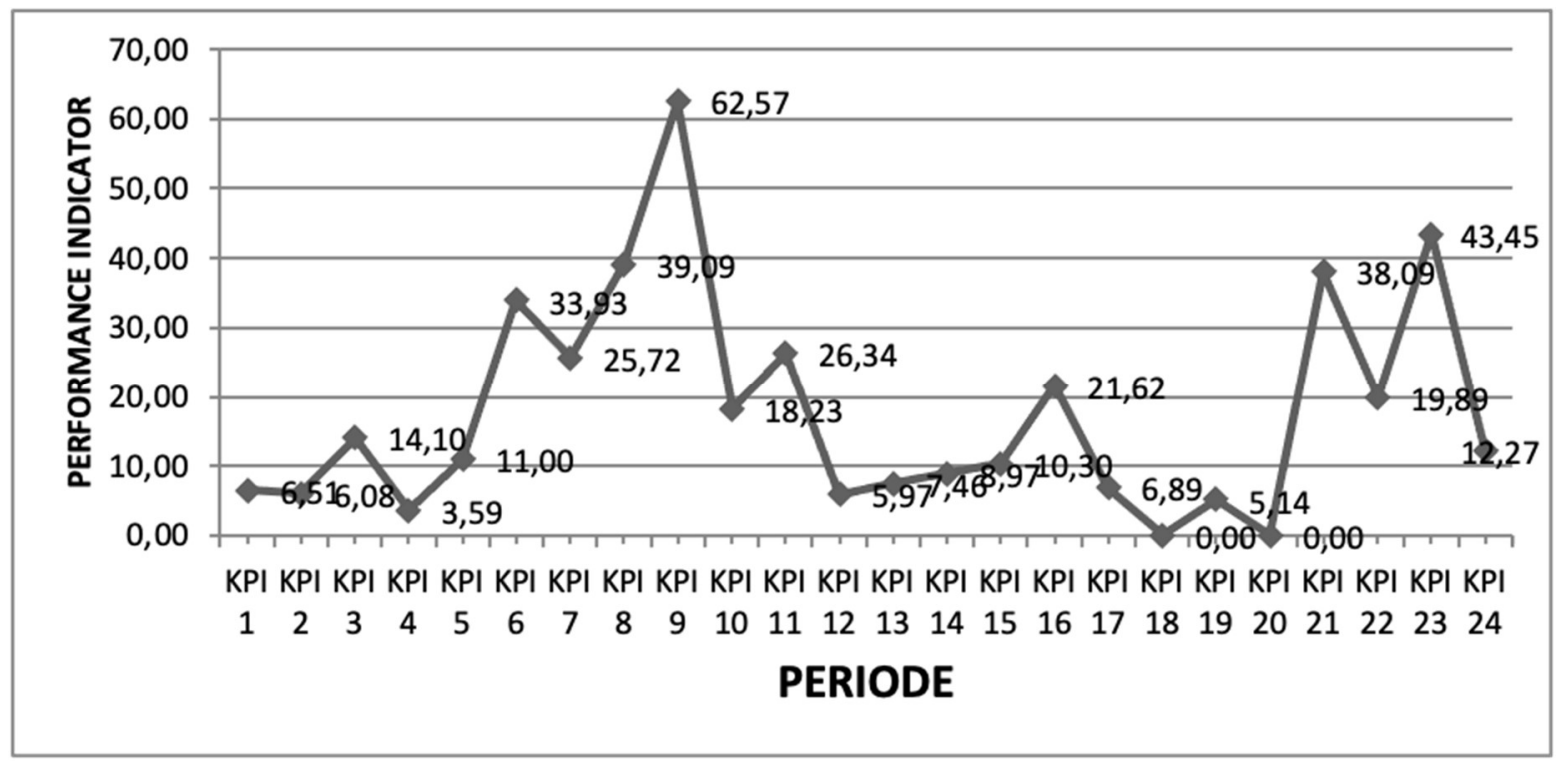

Gambar 1. Grafik Pencapaian Kinerja Seluruh KPI 


\section{Simpulan}

Rancangan Sistem Pengukuran Kinerja dengan mengintegrasikan Malcolm Baldrige Criteria for Performance Excellent (Education Criteria) yang diintegrasikan dengan Metode Objectives Matrix (OMAX), Integrated Performance Measurement Systems (IPMS), Analytical Hierarcy Process (AHP) serta Traffic Light System (TLS) telah berhasil dibuat dengan Performance Indicator Fakultas Teknik adalah 427,19 atau berada $42,4 \%$ diatas nilai rata-rata 300 . Terdapat $21 \% \mathrm{KPI}$ yang temasuk kategori merah, $54 \%$ $\mathrm{KPI}$ yang temasuk kategori kuning, serta $25 \% \mathrm{KPI}$ yang temasuk kategori hijau.

\section{Ucapan Terima Kasih}

Penelitian ini dapat terlaksana dengan baik karena dukungan berbagai pihak. Maka dari itu penulis menyampaikan ucapan terimakasih kepada Direktorat Jendral Pendidikan Tinggi Kemenristek Dikti, LPPM Unud, dan Pimpinan Fak Teknik Unud yang telah membiayai penelitian ini melalui skim Hibah Unggulan Udayana 2018.

\section{Daftar Pustaka}

[1] Sinungan, M, Produktivitas Apa dan Bagaimana, Bumi Aksara, Jakarta, 21 - 53, 2000.

[2] Gazpersz, Vincent, GE Way and Malcomm Baldrige Criteria For Performance Excellence, Gramedian, Jakarta, 195 - 204, 2007.

[3] Coelli T.J, Rao D.S.P, O'Donnell C.J.O, Battese G.E, An Introduction to Efficiency and Productivuty Analysis (Second Edition), Springer Science, 133160, 2005.

[4] Saaty, T.L "Pengambilan Keputusan Bagi Para Pemimpin: Proses Hirarki Analitik untuk Pengambil Keputusan Dalam Situasi yang Kompleks" PT Pustaka Binaman Pressindo, Jakarta , 38 - 65, 1993.

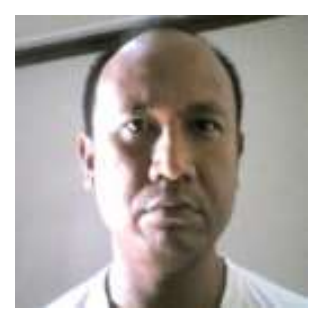

I Made Dwi Budiana Penindra, penulis merupakan dosen tetap pada jurusan Teknik Mesin Universitas Udayana sejak tahun 2003. Pada tahun 2020 telah pindah home base ke Program Studi Teknik Industri Fak Teknik Unud. Lulus sarjana pada tahun 2000 pada jurusan Teknik \& Manajemen Industri Untag Surabaya dan tahun 2002 menyelesaikan S2 di Magister Manajemen Teknologi ITS Surabaya. Penulis memfokuskan pada riset tentang pengukuran kinerja. 